\title{
The Breast Centers That Almost Never Were
}

\author{
Melvin J. Silverstein, MD $^{1,2}$ \\ ${ }^{1}$ Breast Center, Hoag Memorial Hospital Presbyterian, Newport Beach, CA; ${ }^{2}$ Keck School of Medicine, University of \\ Southern California, Los Angeles, CA
}

\section{PROLOGUE}

If you change a single event in a sequence of events that results in an outcome, the outcome likely will be different.

During my 40-year career, I worked at three breast centers. Number one was built from scratch in Van Nuys, California. It was the first free-standing breast center in the United States. ${ }^{1,2}$ There were no models, no prior breast centers to copy, nothing. We made it up as we went along.

The second was at the Norris Comprehensive Cancer Center at the University of Southern California (USC). There was no breast center at USC when I arrived, so that too had to be designed, built, developed, and managed. But this time, we had a model.

The third was at Hoag Memorial Hospital Presbyterian, Newport Beach, California. It was fully formed and functioning when I arrived. My job was to elevate it to the next level, to a breast center of national prominence, and to develop a completely integrated breast program.

During these 40 years, I faced a series of life-changing, life-threatening, career-threatening events, any one of which could have altered the outcome or ended the story at any point in time.

(C) Society of Surgical Oncology 2019

First Received: 26 August 2019;

Published Online: 9 September 2019

M. J. Silverstein, MD

e-mail: melsilver9@gmail.com; melvin.silverstein@hoag.org

\section{THE EPISODE THAT COULD HAVE ENDED EVERYTHING BEFORE IT EVEN BEGAN}

After medical school, I trained in surgery at the Boston City Hospital for 5 years. I did 2 years in the Army followed by a 3-year fellowship in surgical oncology at the University of California, Los Angeles (UCLA). Toward the end of that fellowship, something strange happened.

I noticed that I was not seeing well from my left eye. After a short period of denial, I saw an ophthalmologist, who diagnosed a premature cataract, a disease not common in 35-year-olds. It progressed rapidly, and by the middle of 1975, my eyesight was 20/200 with no binocular vision. This would be an easy fix today, almost a non-issue, a 20-min outpatient surgery with an intraocular lens placement allowing me to be back to work the next day or so. But 45 years ago, things were different. Intraocular lens implants were relatively new and not performed for patients my age. In 1975, this was a disaster for a young surgeon.

I had the cataract removed as an inpatient. When the aphakic eye healed, which took 6 weeks because of the large incision, I had two dramatically different eyes, a minus eye and a plus eye. Each eye saw a different-sized image, and my brain could not fuse the two.

A hard contact lens was prescribed for the aphakic eye, making it reasonably similar to the right eye. It gave me binocular vision, allowing me to operate with bifocals. I tried different contact lenses, but they were extremely uncomfortable, and I wore the lens only during surgery. The rest of the time, I spent my life with monocular vision. I adjusted to it, looking at everything from two or three angles and driving carefully. I lived with it for the next 15 years, as I went about my life. 


\section{THE VAN NUYS BREAST CENTER: THE BREAST CENTER THAT EASILY COULD HAVE NEVER HAPPENED}

During 1977, 1 year after my eye surgery, I visited the CEOs of most Westside hospitals in Los Angeles with an idea: a multidisciplinary breast clinic. Each of them told me it was a good idea, but that it could never work at their hospital. One said, "Our surgeons will eat you alive. The last thing they want is someone from UCLA telling them how to take care of breast cancer. They already know how to take care of breast cancer." I stayed alive by working part-time at the City of Hope, the UCLA School of Public Health, and writing my first novel. ${ }^{3}$

In 1978, I was introduced to the CEO of a hospital in the San Fernando Valley, a place Los Angeles Westsiders considered barely civilized, far enough away that it threatened no Westside physician or hospital. Valley Hospital was 11 miles north of the UCLA Medical Center in Van Nuys, California. It had a brand new 230-bed building that was underutilized. It was relatively empty because the Valley had 37 hospitals at that time (today it has less than half that many), and there was tremendous competition for patients. Valley Hospital needed new programs and new doctors that could attract patients and fill beds. I brought an idea for such a program.

Many women with breast cancer had their diagnosis made in the Valley but were treated over the hill, in Los Angeles. Care was fragmented, with patients going from doctor's office to doctor's office as their workup and treatment plan evolved. A multidisciplinary breast program at Valley Hospital could simplify care and attract many of those out-migrating patients. Most importantly, Valley Hospital did not have a large group of board-certified general surgeons who would be threatened and block an idea like this.

The hospital took a chance. They gave me 3000 square feet in an old, unused building, $\$ 60,000$ to remodel it, and a monthly director's fee for designing the Breast Center and getting it up and running. Without the hospital's financial assistance and the support of a politically savvy Chief of Pathology who wanted the program, the Van Nuys Breast Center would never have happened. With dependable vision in only one eye, I would never have borrowed money to start a vision-dependent surgical venture.

In September 1979, we opened The Breast Center. Because there were no other breast centers, we simply used a generic name. In the future, as competitors developed, the center would become known as the Van Nuys Breast Center.

Local TV stations and newspapers covered the opening. The phones began ringing the next day, and from that point on, the Van Nuys Breast Center was always busy. It filled a previously unrecognized need, that of coordinated and compassionate integrated multidisciplinary breast cancer care.

Initially, I was the only full-time doctor. But I recruited additional specialists, convincing them to spend one or two half days a week with me. This included plastic surgeons, radiation oncologists, medical oncologists, and a psychiatrist. ${ }^{4}$ As the Van Nuys Breast Center developed, we would evolve to 12 fulltime physicians and more than 40 staff.

Because almost everything we did in that era was done in the hospital, our group dramatically improved the hospital census and its bottom line. This led to the development of a six-story medical building on the hospital campus, with the hospital telling us that as soon as the new building was ready, we would have to move into it.

Initially, in the old building, the Breast Center, was owned by the hospital. But when we moved to the new building, it would be owned by the doctors. This move was going to take significant capital. Two of us, the plastic and reconstructive surgeon and I, took a $\$ 600,000$ bank loan, using our homes as collateral. This was a lot of money in 1982, but because the initial version of the Breast Center was successful beyond expectations, I was now willing to take the financial risk despite my aphakic eye.

We opened in the new building in late 1982. Initially, we took the entire top floor, 11,000 square feet, but a few years later, this was no longer enough space. We added an additional 5000 square feet on the floor below for doctors' academic offices, a conference room, and secretarial services. This allowed us to make the top floor entirely clinical (Fig. 1).

Van Nuys was a fertile and creative environment. We started doing oncoplastic surgery in 1985 , long before it was a thing. We published papers dealing with how breast implants could interfere with mammography. ${ }^{5}$ This aroused much anger among Los Angeles plastic surgeons. The ABC television show, 20/20 did a piece on the Van

\section{Van Nuys Breast Center 6th Floor}

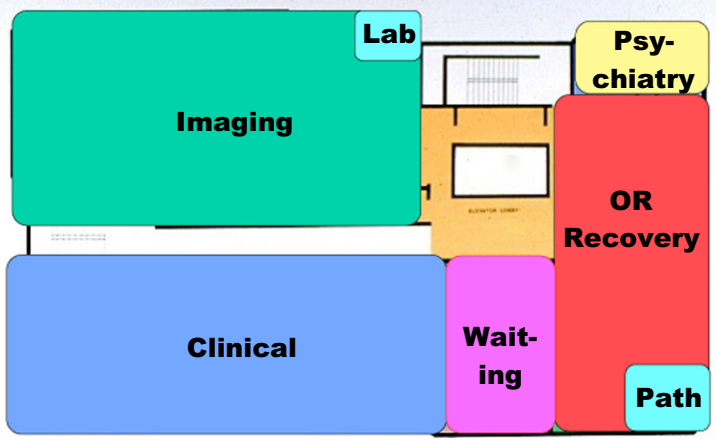

FIG. 1 The revised floor plan of the Van Nuys Breast Center, converting the entire 11,000 -square-foot 6 th floor into clinical space 
Nuys Breast Center and our findings among augmented women. We introduced bracketing guidewires. ${ }^{6} \mathrm{We}$ also became well-known in the ductal carcinoma in situ (DCIS) business and developed the Van Nuys Prognostic Index. ${ }^{7-9}$

We considered moving the Breast Center to a new building, taking an entire 26,000-square-foot floor. However, an analyst advised that insurance reimbursement was about to change (and he was correct) and that we would not be viable in such a large space, so we did not move.

My aphakic eye continued to be a nagging problem. Finally, in 1991, I had a secondary lens implant. I did well for a few months, but unfortunately, the 1975 eye surgeon had removed most of the posterior capsule behind the original lens, leaving almost nothing to hold the artificial lens in place. I blinked one day, and the intraocular lens implant simply flipped back into the posterior chamber. I ended up having a vitrectomy by a retina surgeon. The displaced lens was fished out of the posterior chamber and sutured back into the anterior chamber. I experienced postoperative optic nerve edema and could not see for 3 to 4 weeks. I was worried that I would never operate again. But my vision slowly returned, and I finally got back to work. I now had binocular vision without a contact lens.

My eye was fine until 2014, when the sutures holding the lens in place finally disintegrated. The lens once again fell back into the posterior chamber, this time straight down. The first retina surgeon I saw wanted to operate immediately. The surgery to fish the lens out and suture it back into place was complicated and fraught with the possibility of failure, particularly now that I was older and had undergone multiple prior surgeries on that eye.

The second retina surgeon suggested trying a soft contact lens and following the stability of the displaced lens, and that is what I did. It has worked for 5 years, and that is the way I will finish. At any point in time during the last 40 years, my left eye could have ended my surgical career. That, in turn, would have affected every aspect of this story.

We started collecting data in Van Nuys on an Apple II computer shortly after we opened in 1979. By the time we had been there for 20 years, we had published 90 peerreviewed papers, 80 abstracts, 14 book chapters, and two textbooks, including the first textbook completely devoted to ductal carcinoma in situ of the breast. ${ }^{10}$

As the first free-standing breast center in the United States, Van Nuys became well-known and well-visited. During our tenure, we were visited by hundreds of doctors and administrators from 36 countries and 40 states. We were the model for many subsequent breast centers throughout the world. I was invited to speak all over the globe. All of this led to recruitment by the University of Southern California.
In 1994, the Northridge Earthquake struck at 4:31 a.m. on January 18. The Van Nuys Breast Center was severely impacted. Four mammography machines that were not bolted to the floor, because it was not standard at that time, toppled over and could have severely injured or even killed the patients clamped within them had the event occurred during normal work hours. Shelves, books, drugs, supplies, records, everything, was thrown to the floor. The air conditioners on the roof, although strapped down, tore free, resulting in broken water pipes. The entire sixth floor of the building was flooded. We were closed during the next 6 weeks for repairs. When we reopened, we realized that we needed to be part of a larger financial entity, so we undertook negotiations with Salick Healthcare. We sold the Van Nuys Breast Center in 1996. Salick Healthcare purchased the physical plant and the technical component. The doctors kept ownership of the practice.

The Van Nuys Breast Center did not work as well financially for Salick Healthcare as it had when it was privately owned. By 1998, Salick Healthcare decided to close the facility. The radiologist bought the imaging component and stayed. The remaining physicians went their separate ways. The closing of Van Nuys gave me the opportunity to go to USC.

\section{THE NORRIS CANCER CENTER, KECK SCHOOL OF MEDICINE, UNIVERSITY OF SOUTHERN CALIFORNIA, AND ITS DISASTERS}

I was recruited to USC as full Professor of Surgery and the Henrietta C. Lee Chair in Breast Cancer Research. The University of Southern California gave me a platform from which to speak. It gave me medical students and residents to teach. It gave me credibility. I had become well-known in Van Nuys, but the Van Nuys Breast Center was a private facility. The University of Southern California was a major university and that affiliation took me to another level. As an example, after revisions by a USC statistician, a paper I had written in Van Nuys on DCIS margin width was now accepted by the New England Journal of Medicine. ${ }^{11}$

The happiness of that acceptance did not last long. On Sunday, 15 November 1999 at 9 a.m., I got a call from my ex-wife in New York City telling me that my 17-year-old daughter, Sara, my only biologic child, was dead of a drug overdose. The news was shocking... crushing... devastating. Yet, I went to work the next day. I went to the operating room for safety and control, a place where I could focus on something else. Sara was buried 4 days later, on November 19th, her 18th birthday.

All did not go smoothly for me after Sara's death. In July 2002, on a Wednesday, I had hematuria. On Thursday, I had five cases scheduled. When the first case was 
finished, a computed tomography (CT) scan showed an $8-\mathrm{cm}$ right renal tumor. "Looks like a renal cell" the radiologist said. I felt weak. An acquaintance of mine had received a renal cell carcinoma diagnosis 2 years earlier and had died 18 months later. I called my wife and told her. She told me to come home, but I had four more cases to do. I did not finish until 5 p.m. I was afraid all day. One of the radiologists told the USC Norris Breast Center administrator, "Your boss is a goner."

A few days later, on Monday, I underwent a right radical nephrectomy. The final pathology turned out to be an oncocytoma. So I was not a "goner." I was lucky! I had one postoperative complication, intractable gastroesophageal reflus disease (GERD), secondary to the loss of duodenal motility or weakening of the gastroesophageal junction. It would profoundly degrade my life for the next 3 years and bring occasional thoughts that death might be better. Those of you with bad GERD will understand this.

While I was in the hospital on 2 August 2002, the second edition of the DCIS book was officially published with a dedication to Sara. ${ }^{12}$ After her death, the dedication became the purpose of the book for me. I cried when I wrote it:

\section{To My Daughter \\ Sara Silverstein \\ 1981-1999 \\ Artist \\ Angel \\ Beautiful Child \\ Too much work \\ Patients first \\ Too little time \\ Nothing I can change \\ Much I would change \\ Sara, I love you and I miss you \\ Wait for me}

I went to an internist about 9 months after the nephrectomy. He heard a loud mitral insufficiency murmur that had never been heard before. An echocardiogram (ECHO) showed grade 4 mitral and grade 3 aortic insufficiency. I scheduled the surgery for June 2003 but did not feel well enough to go through with it. I rescheduled for November 2003, and because the GERD was getting better at that point, I had the surgery.

The surgery went well. The surgeon was able to repair both valves. But my blood pressure stayed low. That night, the cardiovascular fellow ordered a chest $\mathrm{x}$-ray, which showed my mediastinum filled with blood. I went back to the operating room. I came out 10 hours later, after 20 units of blood and multiple bags of platelets, with a Dacron ascending aorta but still alive. It took 2 hours of pressure to stop the bleeding from every suture hole. The aortotomy had torn apart and could not be repaired, necessitating replacement of the ascending aorta. How this was done successfully, in the middle of the night, without a full team, amazes me to this day. For 2 or 3 years, when I went to sleep, I thought about the Dacron graft simply ripping apart at the suture line.

The work went on. By the time I left USC in 2008, we had started an oncoplastic breast fellowship, trained 16 oncoplastic fellows, and published 64 additional papers, 30 book chapters, and the second edition of the DCIS book. ${ }^{12}$ I had given hundreds of lectures all over the world, and we had tripled the number of new breast cancer patients at the USC Norris Comprehensive Cancer Center, many of whom were from Orange County. This out-migration from Orange County to USC led to my recruitment by Hoag.

\section{RECRUITMENT TO HOAG}

Sometime in mid-2007, I received a phone call from the Chief of Breast Imaging at Hoag. During that phone call, I was invited to visit Hoag and consider the possibility of relocating there. I thought it was a silly request. I was happy at USC. I was a tenured professor. I ran a major program. I was invited to speak everywhere, multiple times a year. Why would I want to leave? I thanked him and declined the visit, but my wife suggested that I go.

About 1 month later, I drove to Newport Beach. I found a beautiful campus overlooking the Pacific Ocean and the new Bill and Sue Gross Women's Pavilion. The Hoag Breast Center was on the first floor. It was an 11,000square-foot facility with a seamless flow between radiology and surgery. It was bigger, better, and nicer than the 3000-square-foot breast center that I ran at USC. It had many similarities to the Van Nuys Breast Center.

I liked the Hoag Breast Center, and I left with an open mind. This led to a number of phone calls, additional visits, and finally a job offer. My wife and I were fearful about completely changing our lives, giving up Los Angeles, abandoning everything we had known for the last 30 years. But in the end, we overcame our fears and we tried something new. We accepted the job, and we moved.

At a meeting with the Hoag Hospital CEO, he asked, "Can you raise this breast program to the next level?"

I was familiar with the next level. I had moved from Van Nuys to USC.

But I asked, "What is the next level?"

"I don't really know", he said. "That's why we want you." 


\section{THE NEXT LEVEL}

The next level is different for everyone, for every hospital, for every program. It depends on what you currently have and where you would like to be in the future. For Hoag, I thought the next level was a completely integrated multidisciplinary program recognized on the national stage.

\section{HOAG}

I arrived in March 2008. I took the Director's Office in the Hoag Breast Center and started work. I saw patients, I operated, and I began development of a document entitled "Raising the Hoag Breast Program to the Next Level: A Multi-Opportunity Proposal." I finished the document in 3 months and presented it to the administration. It contained multiple items for Hoag's growth or improvement. During the next 10 years, we accomplished most of them. We improved the physical plant, improved safety and communication with the Flight Plan (Fig. 2), updated all the equipment, opened new breast care and imaging facilities, and added amazing new doctors.

We organized the Orange County Breast Consortium, a group of 50 Orange County physicians involved in breast cancer treatment that currently meets three times a year. We developed six incredible new programs including oncoplastic breast surgery, extreme oncoplasty (saving breasts that generally require a mastectomy), ${ }^{13,14}$ and intraoperative radiation therapy (we have become the largest-volume program in the United States, with more than 1300 patients treated through 2019). ${ }^{15}$ We developed a high-risk clinic, a survivorship/thrivorship program, and the jewel in the crown, an oncoplastic surgical breast fellowship associated with USC. We have trained 37 oncoplastic breast fellows at Hoag, bringing our total to 51 fellows, and have sent them all over the country to treat women with breast cancer and to train other physicians (Fig. 3).

At Hoag, we published 41 additional papers and 16 book chapters, and I co-edited my third textbook, Breast Cancer: A New Era in Management. ${ }^{16} \mathrm{We}$ organized and hosted the Third International Consensus Conference on Image-Detected Breast Cancer, and we changed the standard of care for image-detected breast lesions. ${ }^{17} \mathrm{We}$ created and distributed, free-of-charge, two oncoplastic videos, ${ }^{18,19}$ and we guaranteed Hoag's position on the national stage for the next 10 years by endowing the Hoag Surgical Innovation Forum at the Annual Meeting of the American Society of Breast Surgeons with my endowed chair funds and more.
Name. MR Number

Date

Diagnosis: Age 46. LEFT invasive ductal carcinoma, ER/PR Pos, SBR 6/9, HER2 Neg, Ki67 $=10 \%$, 3:00 position, $3 \mathrm{~cm}$ from nipple, Main lesion spanning $21 \mathrm{~mm}$ on mammogram. Skin to tumor distance $11 \mathrm{~mm}$. MRI shows 2 well defined 2-3 $\mathrm{mm}$ nodules adjacent to main tumor. All lesions span $36 \mathrm{~mm}$

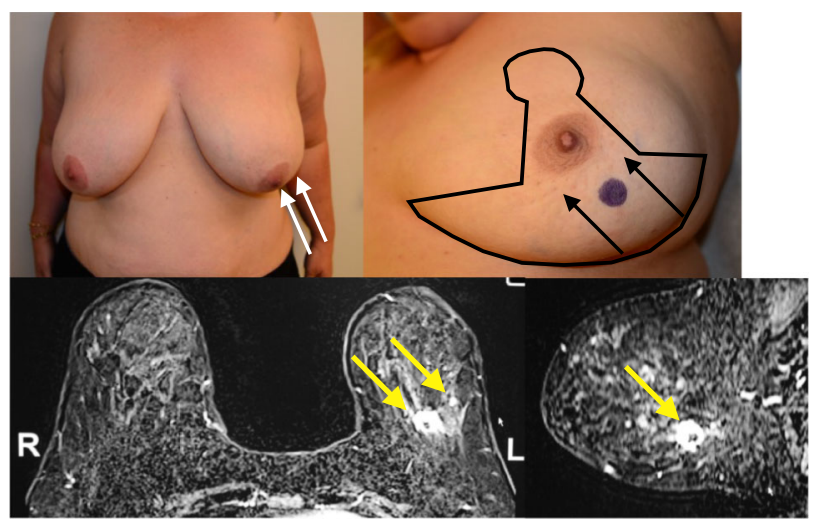

1.LEFT wire directed excision using a reduction

2.LEFT sentinel node excision with additional nodes if positive

3.RIGHT reduction for symmetry and risk reduction

4.Dr.Savalia - Plastic Surgery

5.Genetic counseling - Negative

FIG. 2 In 2008, The Flight Plan, a document detailing the nature of the problem and how it would be handled, was instituted. The Flight Plan puts details of the patient and her cancer at the top, images in the middle, and a plan of action at the bottom. This document is sent electronically to all consultants and staffers on a need-to-know basis and physically travels with the patient from consultation to consultation. It is updated and re-circulated as changes in the treatment plan are made. The Flight Plan always goes to the breast imagers and to the operating room with the patient, guaranteeing that wires are placed from the proper direction and that a wrong-side surgery or incorrect operation never can occur

\section{EPILOGUE}

After 40 years and three breast centers, the diagnosis, treatment, and understanding of breast cancer has changed dramatically. I started my career by removing every breast I treated. I am finishing by saving almost every breast I treat.

I faced a number of personal challenges along the way, any one of which could have ended my career or dramatically altered the story, at just about any point in time. It has been the greatest honor of my life to have worked with amazing young surgeons, brilliant colleagues, and staffs, to have participated in the education of 51 breast fellows, and to have cared for thousands of incredible women, each with her own unique story. 


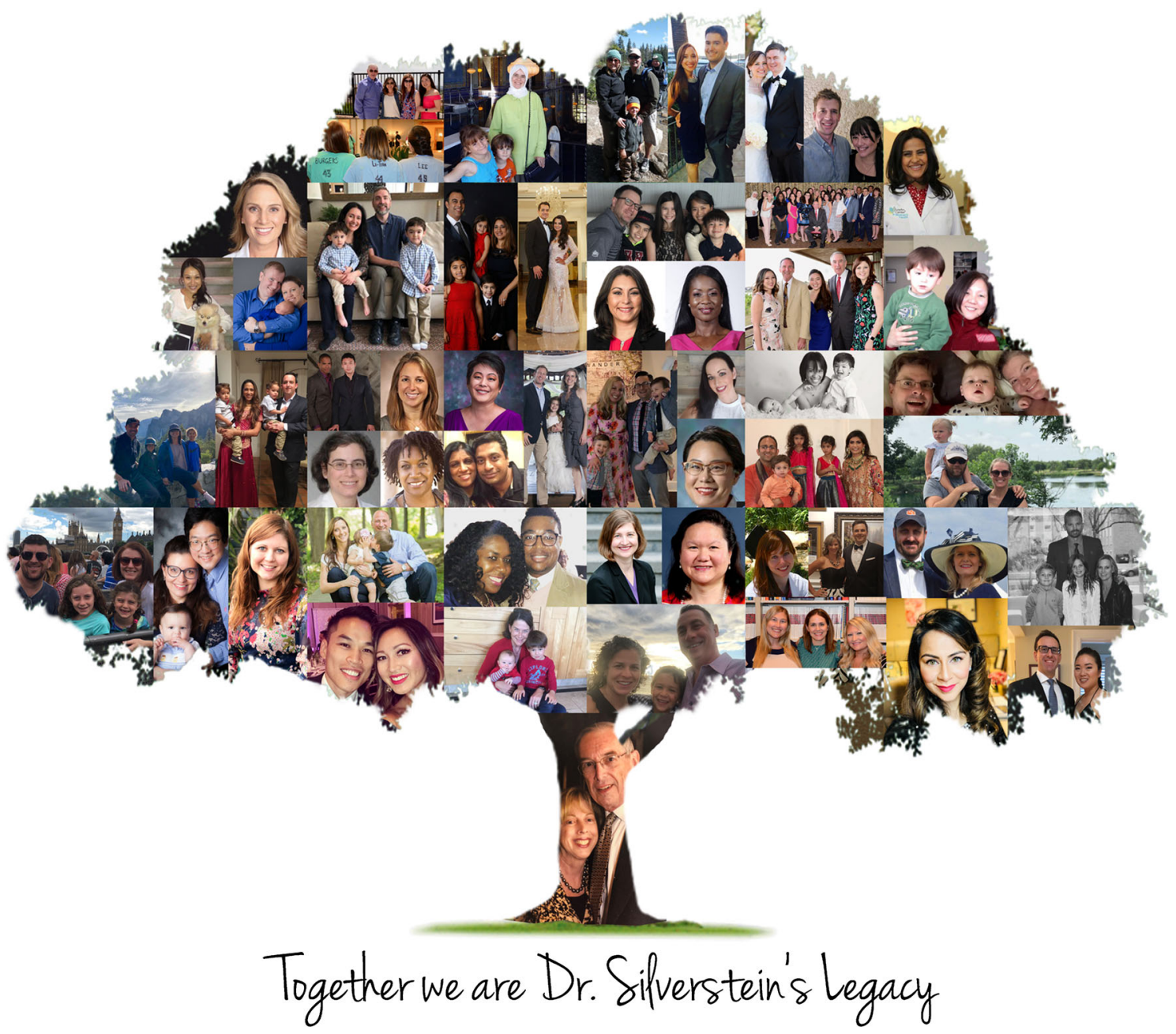

FIG. 3 The Silverstein Legacy Tree, a gift of the 2018 graduating fellows, shows all 51 fellows trained in the USC/Hoag program

If I could replay my life, I would do a few personal things differently, but I would change little about my professional career.

ACKNOWLEDGMENT Throughout the 40-year journey, I was accompanied by Constance Saint Albin. She ran all three breast centers. She oversaw design, development, and change, and she managed all personnel. Most importantly, she kept everyone doing the right thing. She was fearless at that. It is with great admiration and respect that I thank her. I thank Robert Rosser, MD, the politically savvy Chief of Pathology at Valley Hospital, Van Nuys, CA. I thank the original core medical team at Van Nuys: Neal Handel, MD, James Waisman, MD, Parvis Gamagami, MD., Robert Hoffman, MD, Eugene Gierson, MD, Jerry Colburn, MD, Robert Rosser, MD, Barbara Brighton, MFCC, Ellen Waisman, BA, Bernard Lewinsky, MD, and J. Arthur Jensen, MD. Without this group of talented and devoted professionals, not much would have happened. At Hoag, I thank the amazing Nirav Savalia, MD, a kind, patient, incredible and creative reconstructive surgeon. I give a very special thanks to my wife, Lynna Silverstein, for reviewing almost 20 versions of this manuscript and for loving and supporting me through the good times and the bad.

DISCLOSURE There are no conflicts of interest.

\section{REFERENCES}

1. Silverstein MJ. The Van Nuys Breast Center: the first free-standing multidisciplinary breast center. Surg Oncol Clin North Am,. 2000;9:159-75.

2. Silverstein MJ, Handel N, Hoffman R, et al. The breast center: a multidisciplinary model. In: Paterson AHG (ed) Fundamental problems in breast cancer. Martinus Nijhoff, Boston, 1987, pp 47-58.

3. Silverstein MJ, Sperling KJ. Side Effects. Doubleday, Garden City, NY, 1978.

4. Hoffman R. Psychological impact of noninvasive breast cancer. In: Silverstein MJ (ed) Ductal cacrinoma in situ of the breast. Williams and Wilkins, Baltimore, MD, 1997, pp 307-314.

5. Handel N, Silverstein M, Gamagami P, Collins A, Jensen J. Factors affecting mammographic visualization of the breast after augmentation mammoplasty. J Am Med Assoc. 1992;268:1913-7.

6. Silverstein M, Gamagam P, Rosser R, Gierson E, Colburn W, Handel N, et al. Hooked wire-directed biopsy and overpenetrated mammography: 653 consecutive cases. Cancer. 1987;59:715-22.

7. Silverstein MJ. The University of Southern California/Van Nuys Prognostic Index for Ductal Carcinoma In Situ of the Breast. Am J Surg. 2003;186:337-43.

8. Silverstein MJ, Lagios M, Craig P, et al. The Van Nuys prognostic index for ductal carcinoma in situ. Breast J. 1996;2:38-40. 
9. Silverstein MJ, Poller D, Craig P, Waisman J, Lewinsky B, Colburn W, Poller D. A prognostic index for ductal carcinoma in situ of the breast. Cancer. 1996;77:2267-74.

10. Silverstein MJ, Lagios M, Recht A (eds.). Ductal carcinoma in situ of the breast. 1st ed. Williams and Wilkins, Baltimore, 1997.

11. Silverstein MJ, Lagios M, Groshen S, Waisman J, Lewinsky B, Martino S, et al. The influence of margin width on local control in patients with ductal carcinoma in situ (DCIS) of the breast. New Engl J Med. 1999;340:1455-61.

12. Silverstein MJ, Lagios M, Recht A (eds.). Ductal carcinoma in situ of the breast. 2nd ed. Lippincott Williams and Wilkins, Philadelphia, 2002.

13. Silverstein MJ. Radical mastectomy to radical conservation (extreme oncoplasty): a revolutionary change. J Am Coll Surg. 2016;222:1-9.

14. Silverstein MJ, Savalia N, Khan S, Ryan J. Extreme oncoplasty: breast conservation for patients who need mastectomy. Breast $J$. 2015;21:52-9.
15. Silverstein MJ, Epstein M, Kim B, Lin K, Khan S, Snyder L, et al. Intraoperative radiation therapy (IORT): a series of 1000 tumors. Ann Surg Oncol. 2018; 25:2987-93.

16. Francescatti D, Silverstein MJ. Breast cancer: a new era in management. Springer, New York, 2014.

17. Silverstein MJ, Recht A, Lagios M, Bleiweiss I, Blumencranz P, Gizienski T, et al. Image-detected breast cancer: state-of-the-art diagnosis and treatment. Consensus conference III. J Am Coll Surg. 2009;209:504-20.

18. Silverstein MJ. Silverstein's oncoplstic breast surgery. Distributed by Vector Surgical, Inc., Lange Productions, 2010: 2 hours.

19. Silverstein MJ, Savalia NB. Silverstein and Savalia's advanced oncoplastic breast conservation. Distributed by Vector Surgical Inc., Lange Productions, 2015: 2 hours.

Publisher's Note Springer Nature remains neutral with regard to jurisdictional claims in published maps and institutional affiliations. 